\title{
Insulin Resistance and Cognitive Functions in a Sample of Prefrail, Frail and Non-Frail Elderly
}

\author{
Moatassem S. Amer1' ${ }^{1}$ Mohamed S. Khater ${ }^{1}$, Nermien N. Adly ${ }^{1 *}$, Mohamed O. El Maraghy ${ }^{2}$ \\ ${ }^{1}$ Geriatrics and Gerontology Department, Faculty of Medicine, Ain Shams University, Abbassia, Cairo, Egypt \\ ${ }^{2}$ Clinical Pathology Department, Faculty of Medicine, Ain Shams University, Abbassia, Cairo, Egypt \\ Email: ${ }^{*}$ drnermienadly@yahoo.com
}

Received 15 April 2014; revised 15 May 2014; accepted 26 May 2014

Copyright (C) 2014 by authors and Scientific Research Publishing Inc.

This work is licensed under the Creative Commons Attribution International License (CC BY). http://creativecommons.org/licenses/by/4.0/

(c) (i) Open Access

\begin{abstract}
Aim: To study the association between Insulin Resistance (IR) and Glycosylated hemoglobin (HbA1c) and cognition in frail, pre-frail and non-frail elderly. Method: A case control study was conducted on 85 subjects: 60 cases ( 37 frail and 23 pre-frail subjects) and 25 controls. All subjects underwent comprehensive geriatric assessment including a battery of cognitive tests. Laboratory data included Serum insulin levels, Fasting Blood Sugar, Insulin like Growth Factor-1, C-Reactive Protein (CRP) and HbA1c. Results: Among the pre-frail subjects, Homeostasis Model of Assessment-Insulin resistance (HOMA-IR) and insulin level were positively correlated with Digit Span Backward (DSB) ( $p=0.012$ and 0.045 respectively). HbA1c was positively correlated with Contrast Programming (CP) $(p=0.01)$. Controls showed a positive correlation between HOMA-IR and CP, DSB and Mini-Mental Status Examination ( $P=0.009,0.03$ and 0.002 respectively). There was no significant correlation in the frail group. Conclusion: In the studied sample, higher insulin, HbA1c, and IR were associated with better cognitive functions in prefrail elderly, and were not associated with worse cognition in frail elderly.
\end{abstract}

\section{Keywords}

Insulin, Insulin Resistance, Cognition, Elderly, Frailty

\section{Introduction}

Insulin has a complex role in regulation of energy homeostasis and in anabolic actions in peripheral tissues. Stu-

"Corresponding author. 
dies on molecular basis disclosed that insulin is found in many areas of the brain acting as a neuromodulator [1], neuroprotective [2] and neurotrophic mediator [3].

There is a linear correlation between plasma and cerebrospinal fluid insulin concentration in sheep with increasing nutrition, which provides further evidence for insulin transfer through the blood brain barrier, even with increasing insulinemia [4].

Almost all of the central insulin, which exerts its effects within the Central Nervous System (CNS), is of peripheral origin [5] [6].

Brain areas, which are important in cognitive tasks, have high concentrations of insulin receptors, suggesting that insulin might modulate memory by activity at specific central sites. In animal models, acute rise in cerebral intra-ventricular insulin enhances memory during a passive-avoidance task [7].

Insulin resistance [IR] occurs as individuals age and it is related to many of the physical features of frailty such as skeletal muscle weakness, disability in lower extremity mobility, and body composition changes [8]. Frailty was defined as a clinical syndrome in which three or more of the following criteria were present: Shrinking; poor endurance and energy; slowness; weakness and low physical activity [9]. Furthermore, frailty is linked to cognitive decline [10].

Our hypothesis is that peripheral hyperinsulinemia (in the form of IR) could be associated with better cognition in frail and prefrail elderly.

This hypothesis was based upon the favorable impact of IR upon cognition in those with Alzheimer dementia (AD), which is characterized by impaired CNS insulin signaling [11], as Burns et al. [12] proved recently that higher glucose and insulin levels, as a compensation for the impaired insulin signaling, were accompanied by slower cognitive decline in early $\mathrm{AD}$ subjects. This was strengthened by their longitudinal imaging results in which higher peripheral insulin and glucose levels, in their cohort sample after follow up for 2 years, were accompanied by lower rates of whole and regional brain atrophy.

Similarly, impaired CNS insulin signaling is suspected to occur in frailty syndrome. This could be suspected from the decline of physical activity [9], and the increase of the inflammatory markers in frailty syndrome [13].

It was proved that exercise increases insulin signaling in the brain through increasing insulin receptors in the hippocampus [14].

It was found that C-Reactive Protein (CRP) impairs insulin signaling [15].

It is known that with increasing frailty, and decreasing physical activity, there is an increase in CRP [13].

Furthermore, Insulin like Growth Factor-1 (IGF-1) level is a key mediator of the ability of physical activity to enhance neurogenesis in the dentate gyrus of the hippocampal formation [16]. In addition, lower IGF-1 is linked to the frailty syndrome [17]. Therefore, neurogenesis is suspected to be suppressed.

\section{Purpose of the Study}

There is scanty available data about insulin and glucose levels and cognition in the frail elderly in Egypt. Hence, the aim of this study was to disclose the relationship between serum insulin, IR, Fasting Blood Sugar (FBS), glycosylated hemoglobin (HbA1c), CRP, IGF-1levels and cognitive functions in frail, pre-frail and non-frail elderly.

\section{Subjects and Mehods}

\subsection{Study Design}

A case-control study was conducted on 85 subjects aged 60 years and older who were recruited from the outpatient clinic of geriatric medicine department, Ain Shams University Hospital, from May to October 2013.

Cases were 60 subjects who were divided into 37 frail and 23 pre-frail subjects, according to the criteria of Avila-Funes et al. [9] Controls were 25 subjects without frailty. All subjects who could not co-operate to perform the cognitive tests or had medical conditions that could affect the performance of tests were excluded.

Cases with Diabetes Mellitus (DM) were not excluded based on the fact that IR may be considered as a pivotal biological component of some clinical aspects of the frailty syndrome in aging individuals [18]. Therefore, excluding patients with DM could represent a bias in the form of excluding patients with prolonged frailty.

Patients with impaired Mini-Mental Status Examination (MMSE) screening test [19], after adjustment for age and education, were excluded. The research Protocol was approved by the Ethical Committee of the Faculty of 
Medicine, Ain Shams University. Each subject gave informed consent and patient anonymity was preserved. All subjects underwent comprehensive geriatric assessment, including Arabic version of Geriatric Depression Scale 15-items (GDS-15), results $\geq 5$ were considered positive for depression [20].

\subsection{Assessment of Frailty}

Frailty was defined according to the construct previously validated by Fried et al. [21] in the Cardiovascular Health Study. All five components from the original phenotype were retained; however, the metrics used to characterize the frailty criteria were slightly different and defined as follows [9]:

Shrinking: Recent and unintentional weight loss of $\geq 3$ kilograms (Kg) in the prior year was identified and body mass index was calculated. Participants who answered "yes" for weight loss or had a body mass index < $21 \mathrm{~kg} / \mathrm{m}^{2}$ were considered to be frail for this component.

Poor endurance and energy: As indicated by self-report of exhaustion, identified by two questions from the Center for Epidemiological Studies-Depression scale [22]: "I felt that everything I did was an effort" and "I could not get going.” Participants were asked: "How often, in the last week, did you feel this way?” 0 = rarely or none of the time; 1 = some or a little of the time; 2 = a moderate amount of the time; or 3 = most of the time. Participants answering " 2 " or " 3 " to either of these questions were considered as frail for this component.

Slowness: Meets criteria for frailty if time to walk 6 meters was $>8$ seconds for height $\leq 173$ centimeters (cm) or $>7$ seconds for height $>173 \mathrm{~cm}$ in males, and $>8$ seconds for height $\leq 159 \mathrm{~cm}$ or $>7$ seconds for height $>$ $159 \mathrm{~cm}$ in females.

Weakness: Participants answering "yes” to the following question were categorized as frail for this component: "do you have difficulty rising from a chair?"

Low physical activity: A single response was used to estimate physical activity. Individuals who denied doing daily leisure activities such as walking or gardening and/or denied doing some sport activity per week were categorized as physically inactive. Those who reported doing them were considered to be physically active.

As proposed by Fried and colleagues, the participants were considered to be "frail" if they had three or more frailty components among the five criteria; they were considered "prefrail" or "intermediate" if they fulfilled one or two frailty criteria, and "nonfrail” if none.

\subsection{Cognitive Tests}

Apart from MMSE test [19], a battery of cognitive tests was administered including Verbal Fluency (VF) test in which subjects had to enumerate as many animals (four legged) as possible within one minute [23]; Digit Span Forward (DSF) test [24], and Digit Span Backward (DSB) test [24], these tests were done through repetition of numbers in order (DSF) and in reverse order (DSB); Block Design (BD) test that requires the subject to use three-dimensional blocks to construct a model from a two-dimensional stimulus card [24], performance is timed. Although bonus points are awarded for speed, the score is either all or none, that is, a score is awarded only if the model is correctly produced within the prescribed time limit; and contrast Programming (CP) test [25], in which the examiner will randomly hold up either one or two fingers; the patient is instructed to do the opposite, i.e., to hold up two fingers when the examiner holds up one or vice-versa. Ten trials were done; patient is scored according to the number of true trials.

\subsection{Activities of Daily Living and Instrumental Activities of Daily Livings}

Activities of daily living (ADL) [26] and Instrumental Activities of Daily Livings (IADL) [27] were used to assess the ability of the patient to complete basic and advanced self care tasks consecutively.

\subsection{Laboratory Investigations}

Laboratory investigations included measurement of; serum insulin, CRP, HbA1c, FBS, and IGF-1 levels. They were measured as follows: Samples: $5 \mathrm{~mL}$ of whole blood was drawn from each participant after 8 hours fasting, and were divided into 2 tubes: $1 \mathrm{~mL}$ in Ethylene diamine tetraacetic acid anti-coagulated tube for HbA1c assay, and $4 \mathrm{~mL}$ allowed to clot in a plain tube. The resulting serum was used for immediate assay of FBS and quantitative CRP, and the remaining serum was frozen to $-70^{\circ} \mathrm{C}$ till assay of insulin and IGF-1. 


\subsection{Laboratory Analysis}

HbA1c was assayed by ion-exchange chromatographic separation and colorimetric detection kit (Biosystems, SA, Barcelona, Spain). FBS was assayed on Synchron CX-5 autoanalyzer using manufacturer's reagents (Beckman Instruments Inc., Fullerton, USA). Quantitation of CRP was performed by immunoturbidimetric assay using Biosystems CRP kit. Insulin and IGF-1 were measured by enzyme-linked immunosorbent assay, using kits supplied by DRG International Inc. (New Jersey, USA). The former is based on sandwich principle, where capture antibodies coated on microtiter wells bind insulin, followed by anti-insulin tracer antibody-conjugate that reacts with its substrate giving a color directly proportional to insulin concentration; whereas the latter is based on competitive principle, where IGF-1 in the sample competes with biotinylated IGF-1 for microtiter-fixed capture antibodies; followed by addition of streptavidin-horseradish peroxidase complex to react with a specific substrate giving a color inversely proportional to the IGF-1 in the sample.

Finally, insulin resistance was assessed using Homeostasis Model of Assessment-Insulin Resistance (HOMAIR) approach, HOMA-IR was calculated as follows FBS $(\mathrm{mg} / \mathrm{dl})) \times$ fasting insulin $(\mu \mathrm{IU} / \mathrm{mL}) / 405$ [28]. HOMAIR is a useful model for assessing IR by a single measurement of FBS and fasting insulin levels [28]. HOMA-IR has been validated using the euglycemic hyperinsulinemic clamp method [29] [30], which is an expensive and invasive gold standard method [31].

\subsection{Statistical Analysis}

Statistical Package for the Social Sciences (SPSS) version 16 (SPSS Inc., Chicago, IL, USA) was used in data analysis. Qualitative data were expressed in the form of number and frequency. Quantitative data were expressed in the form of mean $+/-\mathrm{SD}$. Chi-square test was used to compare between groups. Quantitative data were tested for normal distribution using one sample Kolmogorov Smirnov test; non-parametric data were converted to parametric data by log transformation. Analysis of variance (ANOVA) followed by Least Significant Difference was used to compare between groups and Pearson correlation coefficient was used for correlation.

\section{Results}

The mean age $( \pm$ SD) of the studied group was $68.2 \pm 6.95$ years. Their demographic characteristics are shown [Table 1]. A significant difference was found between frail, pre-frail and controls (non-frail) regarding the following variables; mean age and hypertension distribution ( $\mathrm{P}=0.01$ for both); HOMA-IR and IGF-1levels $(\mathrm{P}=$ 0.003 for both); CRP levels, HbA1c levels and FBS levels ( $<0.001$ for all); CP ( $\mathrm{P}=0.006)$, DSF $(\mathrm{P}=0.007)$, DSB $(P=0.042)$ and VF $(P=0.015)$ [Table 1]. By post Hoc analysis, the only significant data were as follows: frail elderly were significantly older than non-frail elderly $(\mathrm{P}=0.002)$. They had significantly worse performance than both non-frail $(\mathrm{P}=0.003)$ and pre-frail elderly $(\mathrm{P}=0.028)$ in $\mathrm{CP}$ test. As regards DSF, DSB and VF tests; frail elderly performed significantly worse than non-frail elderly ( $\mathrm{P}=0.002,0.012$ and 0.004 respectively). IR as assessed by HOMA-IR was significantly higher in frail and pre-frail than non-frail elderly $(\mathrm{P}<0.001$, and 0.046 respectively). In addition, frail elderly had significantly lower IGF-1 $(\mathrm{P}<0.001)$ and higher CRP $(\mathrm{P}<$ 0.001) and HbA1c $(\mathrm{P}<0.001)$ than non-frail elderly. Furthermore, pre-frail elderly had higher CRP and HbA1c than non-frail elderly ( $\mathrm{P}<0.001$ for both). Frail elderly had significantly higher insulin than non-frail elderly ( $\mathrm{P}$ $=0.043)$. FBS was significantly higher in frail and pre-frail than non-frail elderly ( $P<0.001$ for both).

Regarding the physical activity, there was significant difference between the 3 groups in ADL and IADL scores [Table 1]. By post hoc analysis, frail elderly had significantly worse scores than both prefrail and the control groups in ADL ( $\mathrm{P}<0.001$ for both) and in IADL ( $<0.001$ for both). The prefrail had significantly worse score than the control group in ADL and IADL ( $P=0.05$ and $<0.001$ consecutively).

Using correlation tests, after adjustment for age, gender, and education, CRP in the control group showed a negative correlation with CP, DSB and MMSE ( $\mathrm{P}=0.01,0.001$ and 0.004 respectively). No significant correlations were observed between CRP or IGF-1 and cognition in the frailty group except for a negative one regarding DSB test scores with CRP $(\mathrm{P}=0.045)$ and a positive one for the same test with IGF-1 $(\mathrm{P}=0.002)$, in the pre-frail group [Table 2].

As regards insulin level, HOMA-IR, and HbA1c level, none of them did show a significant correlation with cognitive test results in the frail group. Regarding the pre-frail ones, HOMA-IR and insulin level were positively correlated with DSB ( $\mathrm{P}=0.012$ and 0.045 respectively), while HbA1c level was positively correlated with CP 
Table 1. Data of the whole studied group with comparison between the three studied groups.

\begin{tabular}{|c|c|c|c|c|c|}
\hline Variable & $\begin{array}{l}\text { Whole subjects } \\
\qquad \mathrm{N}=85\end{array}$ & $\begin{array}{l}\text { Frail group } \\
\quad \mathrm{N}=37\end{array}$ & $\begin{array}{l}\text { Pre-frail group } \\
\quad \mathrm{N}=23\end{array}$ & $\begin{array}{c}\text { Control group, } \\
\quad \mathrm{N}=25\end{array}$ & $P$ value \\
\hline Age (mean \pm SD) & $68.2 \pm 6.95$ & $70.35 \pm 8.02$ & $68.30 \pm 6.10$ & $64.8 \pm 4.78$ & 0.010 \\
\hline Gender (male), N (\%) & $41(48.2 \%)$ & 15 (40.5\%) & $12(52.2 \%)$ & $14(56 \%)$ & 0.44 \\
\hline Current smoking, N (\%) & $27(31.8 \%)$ & 7 (18.9\%) & $11(47.8 \%)$ & $9(36.0 \%)$ & 0.056 \\
\hline Illiterate, N (\%) & $22(25.9 \%)$ & $11(29.7 \%)$ & $4(17.4 \%)$ & $7(28 \%)$ & 0.55 \\
\hline Depression, N (\%) & $11(12.9 \%)$ & $2(5.4 \%)$ & $6(26.1 \%)$ & $3(12 \%)$ & 0.07 \\
\hline HTN, N (\%) & $38(44.7 \%)$ & 19 (51.4\%) & $14(60.9 \%)$ & $5(20 \%)$ & 0.010 \\
\hline ADL score $($ mean $\pm \mathrm{SD})$ & $4.9 \pm 1.5$ & $3.8 \pm 1.4$ & $5.3 \pm 1.3$ & $6 \pm 0.0$ & $<0.001$ \\
\hline IADL score (mean \pm SD) & $5 \pm 2.5$ & $3.2 \pm 1.8$ & $5 \pm 1.8$ & $7.7 \pm 1.1$ & $<0.001$ \\
\hline MMSE (mean \pm SD) & $26.81 \pm 3$ & $25.76 \pm 1.88$ & $27.74 \pm 1.61$ & $27.2 \pm 4.25$ & 0.223 \\
\hline $\mathrm{BD}($ mean $\pm \mathrm{SD})$ & $4.21 \pm 4.19$ & $2.81 \pm 3.64$ & $3.91 \pm 3.50$ & $5.63 \pm 4.75$ & 0.351 \\
\hline $\mathrm{CP}($ mean $\pm \mathrm{SD})$ & $7.60 \pm 1.89$ & $6.92 \pm 2.1$ & $7.91 \pm 1.68$ & $7.97 \pm 1.52$ & 0.006 \\
\hline DSF (mean \pm SD) & $4.62 \pm 1.08$ & $4.22 \pm 1.58$ & $4.78 \pm 0.85$ & $5.0 \pm 1.02$ & 0.007 \\
\hline DSB (mean \pm SD) & $2.08 \pm 1.47$ & $1.46 \pm 1.30$ & $2.43 \pm 1.34$ & $2.53 \pm 1.57$ & 0.042 \\
\hline $\mathrm{VF}($ mean $\pm \mathrm{SD})$ & $7.25 \pm 2.78$ & $6.30 \pm 2.15$ & $7.56 \pm 3.16$ & $7.73 \pm 2.98$ & 0.015 \\
\hline HOMA-IR (mean \pm SD) & $2.16 \pm 1.19$ & $2.62 \pm 1.27$ & $2.26 \pm 1.24$ & $1.6 \pm 0.8$ & 0.003 \\
\hline IGF-1 $(\mathrm{ng} / \mathrm{mL})($ mean $\pm \mathrm{SD})$ & $68.79 \pm 26.55$ & $56.81 \pm 20.59$ & $74.00 \pm 30.82$ & $83.20 \pm 22.06$ & 0.003 \\
\hline $\mathrm{CRP}(\mathrm{mg} / \mathrm{L})($ mean $\pm \mathrm{SD})$ & $10.40 \pm 6.26$ & $11.86 \pm 5.61$ & $11.74 \pm 6.53$ & $6.93 \pm 5.32$ & $<0.001$ \\
\hline HbA1c (\%) (mean \pm SD) & $6.68 \pm 1.42$ & $7.05 \pm 1.48$ & $7.26 \pm 1.41$ & $5.89 \pm 0.94$ & $<0.001$ \\
\hline FBS $(\mathrm{mg} / \mathrm{dL})($ mean $\pm \mathrm{SD})$ & $112.64 \pm 22.92$ & $120.57 \pm 23.41$ & $118.04 \pm 22.85$ & $95.92 \pm 11.03$ & $<0.001$ \\
\hline Insulin $(\mu \mathrm{IU} / \mathrm{mL})($ mean $\pm \mathrm{SD})$ & $7.7398 \pm 3.79$ & $8.73 \pm 3.74$ & $8.20 \pm 4.71$ & $6.20 \pm 2.49$ & 0.123 \\
\hline
\end{tabular}

ADL: activities of daily livings, BD: Block Design, CP: Contrast Programming, CRP: C-Reactive Protein, DSB: Digit Span Backward, DSF: Digit Span Forward, FBS: Fasting Blood Sugar, HbA1c: Glycosylated hemoglobin, HOMA-IR: Homeostasis Model of Assessment-Insulin Resistance, HTN: Hypertension, IGF-1: Insulin-like Growth Factor-1, IADL: Instrumental Activities of Daily Livings, MMSE: Mini-Mental Status Examination, VF: Verbal Fluency. SD = Standard Deviation, $\mathrm{N}=$ Number, $\mathrm{mg} / \mathrm{L}=$ Milligrams Per Liter, $\mathrm{mg} / \mathrm{dl}=$ Milligrams per Deciliter, $\mathrm{ng} / \mathrm{ml}=\mathrm{Nanogram} \mathrm{Per}$ Milliliter, uIU/ml = Micro International Units Per Milliliter.

test results $(\mathrm{P}=0.01)$. On the other hand, controls showed a positive correlation between HOMA-IR and the following cognitive tests CP $(P=0.009)$, DSB $(P=0.03)$, and MMSE $(P=0.002)$, while their insulin level was positively correlated with DSB and MMSE ( $\mathrm{P}=0.005$ and $<0.001$ respectively) and finally HbA1c level was positively correlated with DSF $(\mathrm{P}=0.008)$ [Table 3].

\section{Discussion}

After adjustment for age, gender and education, current data revealed that insulin and HOMA-IR were positively correlated with some cognitive tests in non frail subjects, along with HOMA-IR $<2.5$ (a cut off for IR) [32], and combined HbA1c $<6.5$ and FBS $<126 \mathrm{mg} / \mathrm{dl}$, as a combined cut offs for diagnosis of DM in asymptomatic patients [33].

Therefore, IR is associated with better cognition in non frail subjects in the presence of these laboratory parameters.

This is in accordance with Kaplan et al. [34] who conducted a study upon 10 males and 10 females free-living subjects aged 60 - 82 y in whom evidence of DM (FBS $\geq 126 \mathrm{mg} / \mathrm{dl}$ ) or cognitive decline were used as exclusion criteria. They found poor baseline verbal declarative memory (immediate and 20-min delayed paragraph recall and word list recall) and visuomotor task performance were predicted by low IR.

Furthermore, Euser et al. [35] found that elevations in FBS levels are not associated with impaired cognitive function or with an accelerated rate of cognitive decline in subjects without a history of diabetes. In addition, there was no clear relationship between HOMA-IR index and cognitive function and decline in subjects without a history of diabetes. They suggested that cognitive decline is enhanced strongly once a subject is diabetic. 
Table 2. Correlation between CRP, IGF-1 and cognitive tests in each group of the studied population, with adjustment for age, gender and education.

\begin{tabular}{|c|c|c|c|c|c|c|c|}
\hline \multirow{2}{*}{ Variable } & \multirow[t]{2}{*}{$\begin{array}{l}\mathrm{P} \\
\mathrm{r}\end{array}$} & \multicolumn{2}{|c|}{$\begin{array}{l}\text { Frail group } \\
\quad \mathrm{N}=37\end{array}$} & \multicolumn{2}{|c|}{$\begin{array}{l}\text { Pre-frail group } \\
\quad \mathrm{N}=23\end{array}$} & \multicolumn{2}{|c|}{$\begin{array}{l}\text { Control group } \\
\mathrm{N}=25\end{array}$} \\
\hline & & CRP & IGF-1 & CRP & IGF-1 & CRP & IGF-1 \\
\hline $\mathrm{BD}$ & $\begin{array}{l}\mathrm{P} \\
\mathrm{r}\end{array}$ & $\begin{array}{c}0.39 \\
(-0.29)\end{array}$ & $\begin{array}{l}0.12 \\
(0.5)\end{array}$ & $\begin{array}{c}0.22 \\
(-0.35)\end{array}$ & $\begin{array}{c}0.83 \\
(0.063)\end{array}$ & $\begin{array}{c}0.12 \\
(-0.39)\end{array}$ & $\begin{array}{c}0.77 \\
(0.078)\end{array}$ \\
\hline $\mathrm{CP}$ & $\begin{array}{l}\mathrm{P} \\
\mathrm{r}\end{array}$ & $\begin{array}{c}0.96 \\
(0.02)\end{array}$ & $\begin{array}{c}0.2 \\
(-0.42)\end{array}$ & $\begin{array}{c}0.31 \\
(0.29)\end{array}$ & $\begin{array}{c}0.56 \\
(-0.17)\end{array}$ & $\begin{array}{c}0.01 \\
(-0.59)\end{array}$ & $\begin{array}{c}0.39 \\
(0.22)\end{array}$ \\
\hline DSF & $\begin{array}{l}\mathrm{P} \\
\mathrm{r}\end{array}$ & $\begin{array}{c}0.45 \\
(-0.25)\end{array}$ & $\begin{array}{c}0.73 \\
(-0.12)\end{array}$ & $\begin{array}{c}0.58 \\
(0.16)\end{array}$ & $\begin{array}{c}0.33 \\
(-0.28)\end{array}$ & $\begin{array}{c}0.1 \\
(-0.4)\end{array}$ & $\begin{array}{c}0.23 \\
(0.31)\end{array}$ \\
\hline DSB & $\begin{array}{l}\mathrm{P} \\
\mathrm{r}\end{array}$ & $\begin{array}{c}0.21 \\
(-0.41)\end{array}$ & $\begin{array}{l}0.22 \\
(0.4)\end{array}$ & $\begin{array}{c}0.045 \\
(-0.54)\end{array}$ & $\begin{array}{l}0.002 \\
(0.76)\end{array}$ & $\begin{array}{c}0.001 \\
-(0.73)\end{array}$ & $\begin{array}{c}0.13 \\
(0.38)\end{array}$ \\
\hline VF & $\begin{array}{l}\mathrm{P} \\
\mathrm{r}\end{array}$ & $\begin{array}{c}0.18 \\
(-0.44)\end{array}$ & $\begin{array}{c}0.17 \\
(0.45)\end{array}$ & $\begin{array}{c}0.59 \\
(-0.16)\end{array}$ & $\begin{array}{c}0.31 \\
(0.29)\end{array}$ & $\begin{array}{c}0.66 \\
(-0.12)\end{array}$ & $\begin{array}{c}0.42 \\
(-0.21)\end{array}$ \\
\hline MMSE & $\begin{array}{l}\mathrm{P} \\
\mathrm{r}\end{array}$ & $\begin{array}{c}0.07 \\
(-0.56)\end{array}$ & $\begin{array}{c}0.18 \\
(0.44)\end{array}$ & $\begin{array}{c}0.74 \\
(-0.1)\end{array}$ & $\begin{array}{c}0.35 \\
(0.27)\end{array}$ & $\begin{array}{c}0.004 \\
(-0.66)\end{array}$ & $\begin{array}{c}0.28 \\
(0.28)\end{array}$ \\
\hline
\end{tabular}

BD: Block Design, CP: Contrast Programming, CRP: C-Reactive Protein, DSB: Digit Span Backward, DSF: Digit Span Forward, IGF-1: Insulinlike Growth Factor-1, MMSE: Mini-Mental Status Examination, VF: Verbal Fluency.

Table 3. Correlation between HOMA-IR, insulin, and HbA1c levels and cognitive tests results in each group.

\begin{tabular}{|c|c|c|c|c|c|c|c|c|c|c|}
\hline \multirow{2}{*}{ Variable } & \multirow[t]{2}{*}{$\begin{array}{l}\mathrm{P} \\
\mathrm{r}\end{array}$} & \multicolumn{3}{|c|}{$\begin{array}{l}\text { Frail group } \\
\quad \mathrm{N}=37\end{array}$} & \multicolumn{3}{|c|}{$\begin{array}{l}\text { Pre-frail group } \\
\quad \mathrm{N}=23\end{array}$} & \multicolumn{3}{|c|}{$\begin{array}{c}\text { Control group } \\
\mathrm{N}=25\end{array}$} \\
\hline & & HOMA-IR & Insulin & HbA1c & HOMA-IR & Insulin & HbA1c & HOMA-IR & Insulin & HbA1c \\
\hline BD & $\begin{array}{l}\mathrm{P} \\
\mathrm{r}\end{array}$ & $\begin{array}{c}0.63 \\
(-0.16)\end{array}$ & $\begin{array}{c}0.77 \\
(-0.1)\end{array}$ & $\begin{array}{c}0.06 \\
(0.59)\end{array}$ & $\begin{array}{c}0.28 \\
(0.31)\end{array}$ & $\begin{array}{c}0.37 \\
(0.26)\end{array}$ & $\begin{array}{c}0.62 \\
(0.14)\end{array}$ & $\begin{array}{l}0.11 \\
(0.4)\end{array}$ & $\begin{array}{c}0.06 \\
(0.47)\end{array}$ & $\begin{array}{c}0.78 \\
(0.072)\end{array}$ \\
\hline $\mathrm{CP}$ & $\begin{array}{l}\mathrm{P} \\
\mathrm{r}\end{array}$ & $\begin{array}{c}0.06 \\
(0.59)\end{array}$ & $\begin{array}{c}0.67 \\
(-0.15)\end{array}$ & $\begin{array}{c}0.52 \\
(-0.22)\end{array}$ & $\begin{array}{c}0.55 \\
(-0.18)\end{array}$ & $\begin{array}{c}0.24 \\
(-0.34)\end{array}$ & $\begin{array}{c}0.01 \\
(0.66)\end{array}$ & $\begin{array}{l}0.009 \\
(0.61)\end{array}$ & $\begin{array}{c}0.14 \\
(0.58)\end{array}$ & $\begin{array}{c}0.15 \\
(0.37)\end{array}$ \\
\hline DSF & $\begin{array}{l}\mathrm{P} \\
\mathrm{r}\end{array}$ & $\begin{array}{c}0.83 \\
(-0.07)\end{array}$ & $\begin{array}{c}0.75 \\
(-0.11)\end{array}$ & $\begin{array}{c}0.57 \\
(0.19)\end{array}$ & $\begin{array}{c}0.85 \\
(-0.06)\end{array}$ & $\begin{array}{c}0.75 \\
(-0.09)\end{array}$ & $\begin{array}{c}0.23 \\
(0.35)\end{array}$ & $\begin{array}{c}0.32 \\
(0.26)\end{array}$ & $\begin{array}{c}0.11 \\
(0.40)\end{array}$ & $\begin{array}{l}0.008 \\
(0.62)\end{array}$ \\
\hline DSB & $\begin{array}{l}\mathrm{P} \\
\mathrm{r}\end{array}$ & $\begin{array}{c}0.81 \\
(-0.08)\end{array}$ & $\begin{array}{c}0.83 \\
(-0.07)\end{array}$ & $\begin{array}{c}0.93 \\
(0.03)\end{array}$ & $\begin{array}{l}0.012 \\
(0.65)\end{array}$ & $\begin{array}{l}0.045 \\
(0.54)\end{array}$ & $\begin{array}{c}0.46 \\
(-0.25)\end{array}$ & $\begin{array}{c}0.03 \\
(0.53)\end{array}$ & $\begin{array}{l}0.005 \\
(0.65)\end{array}$ & $\begin{array}{c}0.1 \\
(0.42)\end{array}$ \\
\hline VF & $\begin{array}{l}\mathrm{P} \\
\mathrm{r}\end{array}$ & $\begin{array}{c}0.77 \\
(-0.01)\end{array}$ & $\begin{array}{c}0.12 \\
(0.49)\end{array}$ & $\begin{array}{c}0.24 \\
(0.38)\end{array}$ & $\begin{array}{c}0.31 \\
(0.29)\end{array}$ & $\begin{array}{c}0.60 \\
(0.15)\end{array}$ & $\begin{array}{c}0.27 \\
(0.32)\end{array}$ & $\begin{array}{c}0.37 \\
(0.23)\end{array}$ & $\begin{array}{c}0.43 \\
(0.21)\end{array}$ & $\begin{array}{c}0.38 \\
(0.23)\end{array}$ \\
\hline MMSE & $\begin{array}{l}\mathrm{P} \\
\mathrm{r}\end{array}$ & $\begin{array}{c}0.61 \\
(0.18)\end{array}$ & $\begin{array}{c}0.45 \\
(0.26)\end{array}$ & $\begin{array}{c}0.58 \\
(-0.19)\end{array}$ & $\begin{array}{c}0.32 \\
(0.29)\end{array}$ & $\begin{array}{c}0.65 \\
(0.14)\end{array}$ & $\begin{array}{c}0.17 \\
(0.39)\end{array}$ & $\begin{array}{l}0.002 \\
(0.71)\end{array}$ & $\begin{array}{l}<0.001 \\
(0.81)\end{array}$ & $\begin{array}{c}0.15 \\
(0.37)\end{array}$ \\
\hline
\end{tabular}

BD: Block Design, CP: Contrast Programming, DSB: Digit Span Backward, DSF: Digit Span Forward, HbA1c: Glycosylated hemoglobin, HOMAIR: Homeostasis Model of Assessment-Insulin Resistance, MMSE: Mini-Mental Status Examination, VF: Verbal Fluency.

However, there is no decline in cognition with lesser degrees of dysglycemia. Absence of positive association between FBS and HOMA-IR and cognition in Euser et al. [35] study could be attributed in part for excluding diabetic patients only by history.

Our control subjects possess the lowest levels of CRP; which impair the insulin signaling pathway [15], and the highest levels of IGF-1 that play a key mediator of the ability of physical activity to enhance neurogenesis [16]. Therefore, this control group was suspected to have the best neurogenesis and insulin signaling.

In the prefrail subjects, the current results revealed that insulin, HOMA-IR and HbA1c were positively correlated with some cognitive tests, along with some cases that have HOMA-IR $\geq 2.5$, HbA1c $\geq 6.5$ and FBS $\geq 126$ $\mathrm{mg} / \mathrm{dl}$.

There was a positive association between hyperinsulinemia and hyperglycemia, along with the presence of IR and diabetes, and better cognition in prefrail subjects. This could be explained by the benefit exerted by higher peripheral insulin and peripheral hyperglycemia to compensate for lower brain insulin signaling as more energy (in form of glucose) will be diverted to the insulin independent tissues (as brain and red blood cells) and less to tissues which is insulin dependent (as skeletal muscles and liver) [36].

This impacts cognition because insulin receptors are present in many areas of the brain. Insulin and insulin 
receptors in the brain are associated with neuronal development [1]-[3] and have impact upon cognitive functions [7].

This finding is supported by Burns and colleagues in a cohort of early AD, [12] which is known to have impaired CNS insulin signaling [11]. They found that higher peripheral insulin and glucose levels, in their cohort sample after follow up for 2 years, were accompanied by lower rates of whole and regional brain atrophy [12]. This is further supported by 2 further studies suggesting that subjects with type II DM and AD had lower decline in cognition than non-diabetic subjects with AD [37] [38]. Furthermore, intranasal insulin preserved general cognition in mild to moderate AD patients [39]. This refers to the differential relation of insulin and cognition which could help to explain our results.

One of the important factors that decrease brain insulin sensitivity and impair insulin signaling is the increased expression of inflammatory markers within the brain [40], which is the case in frailty and to a lesser extent in pre-frailty. The heightened inflammatory state is observed by the increased levels of molecular and cellular inflammatory markers compared with that observed in non-frail individuals [13].

However, in the frail subjects, the current study found that insulin, HOMA-IR and HbA1c were not positively correlated with cognitive tests, along with some cases that had HOMA-IR $\geq 2.5$, HbA1c $\geq 6.5$ and FBS $\geq 126$ $\mathrm{mg} / \mathrm{dl}$.

This means that insulin, HOMA-IR and HbA1c might have no positive association with cognition in frail elderly in spite of the presence of hyperinsulinemia and the suspected decrease in the brain insulin signaling.

As regards our frail subjects, they are mostly in the zone of not getting benefit from high insulin, HbA1c and IR levels due to decreased physical activity. Our pre-frail subjects showed a statistically significant better performance in ADL than frail subject. Decreased physical activity, as it is the case with frail elderly, has effect on sustaining the vascular health of the brain. Experimental studies have found that physical activity enhances cerebral blood flow, increases cerebral capillary density, and decreases radical oxidative protein deposits [41]. In animal models, exercise enhances concentration of brain-derived neurotrophic factors, in addition to other growth factors, stimulates neurogenesis, enhances resistance to brain insults, and stimulates gene expression that could benefit brain plasticity processes [42]. The suspected decrease of the brain protection in frail subjects could underlie the absence of positive association between cognitive tests and HbA1c and HOMA-IR, despite the presence of hyperinsulinemia and hyperglycemia along with the suspected impaired insulin signaling in the frail subjects.

\section{Conclusion}

In our sample, frail elderly had the worst performance in some cognitive tests. Furthermore, higher insulin, HbA1c, and IR were associated with better cognitive functions in pre-frail elderly, and were not associated with worse cognition in frail elderly. Therefore, insulin may have a differential relation to cognitive functions. The conclusion needs further study before generalizing the sentence as a fact.

\section{Limitations}

The limitations of the current study are the relatively small sample size and not excluding diabetic cases. However, presence of positive correlation between HOMA-IR, insulin, HbA1c and cognitive tests in pre-frail, along with the absence of negative correlation in frail elderly gives further support to our idea that insulin might be associated with better cognition in pre-frail and frail elderly, as it is known that DM impairs cognitive functions [43].

\section{Recommendations}

Future studies could test the causative association between hyperglycemia and hyperinsulinemia and cognition in frail and prefrail subjects. In addition, the impact of intranasal insulin therapy upon cognition in pre-frail and frail subjects might be tested.

\section{Acknowledgements}

We acknowledge all participants in this study, for their gracious help and patience. 


\section{Conflict of Interest}

The authors have no financial interests or any conflicts related to the material in the manuscript.

\section{References}

[1] Gerozissis, K. (2003) Brain Insulin: Regulation, Mechanisms of Action and Functions. Cellular and Molecular Neurobiology, 23, 1-25. http://dx.doi.org/10.1023/A:1022598900246

[2] Schubert, M., Gautam, D., Surjo, D., Ueki, K., Baudler, S., Schubert, D., Kondo, T., Alber, J., Galldiks, N., Küstermann, E., Arndt, S., Jacobs, A.H., Krone, W., Kahn, C.R. and Brüning, J.C. (2004) Role for Neuronal Insulin Resistance in Neurodegenerative Diseases. Proceedings of the National Academy of Sciences, 101, 3100-3105. http://dx.doi.org/10.1073/pnas.0308724101

[3] Tanaka, M., Sawada, M., Yoshida, S., Hanaoka, F. and Marunouchi, T. (1995) Insulin Prevents Apoptosis of External Granular Layer Neurons in Rat Cerebellar Slice Cultures. Neuroscience Letters, 199, 37-40. http://dx.doi.org/10.1016/0304-3940(95)12009-S

[4] Miller, D.W., Bennett, E.J., Harrison J.L., Findlay, P.A. and Adam, C.L. (2011) Adiposity and Plane of Nutrition Influence Reproductive Neuroendocrine and Appetite Responses to intracerebroventricular Insulin and Neuropeptide-Y in Sheep. Reproduction, Fertility and Development, 23, 329-338. http://dx.doi.org/10.1071/RD10150

[5] Gerozissis, K. and Kyriaki, G. (2003) Brain Insulin: Regulation, Mechanisms of Action and Functions. Cellular and Molecular Neurobiology, 23, 1-25. http://dx.doi.org/10.1023/A:1022598900246

[6] Laron, Z. (2009) Insulin and the Brain. Archives of Physiology and Biochemistry, 115, 112-116. http://dx.doi.org/10.1080/13813450902949012

[7] Park, C.R., Seeley, R.J. and Craft, S. (2000) Intracerebroventricular Insulin Enhances Memory in a Passive-Avoidance Task. Physiology \& Behavior, 68, 509-514. http://dx.doi.org/10.1016/S0031-9384(99)00220-6

[8] Abbatecola, A.M. and Paolisso, G. (2008) Is There a Relationship between Insulin Resistance and Frailty Syndrome? Current Pharmaceutical Design, 14, 405-410. http://dx.doi.org/10.2174/138161208783497750

[9] Avila-Funes, J.A., Helmer, C., Amieva, H., Barberger-Gateau, P., Le Goff, M., Ritchie, K., Portet, F., Carrière, I., Tavernier, B., Gutiérrez-Robledo, L.M. and Dartigues J.F. (2008) Frailty among Community-Dwelling Elderly People in France: The Three-City Study. The Journals of Gerontology Series A: Biological Sciences and Medical Sciences, 63, 1089-1096. http://dx.doi.org/10.1093/gerona/63.10.1089

[10] Samper-Ternent, R., Al Snih, S., Raji, M.A., Markides, K.S. and Ottenbacher, K.J. (2008) Relationship between Frailty and Cognitive Decline in Older Mexican Americans. Journal of the American Geriatrics Society, 56, 1845-1852. http://dx.doi.org/10.1111/j.1532-5415.2008.01947.x

[11] Craft, S., Peskind, E., Schwartz, M.W., Schellenberg, G.D., Raskind, M. and Porte Jr., D. (1998) Cerebrospinal Fluid and Plasma Insulin Levels in Alzheimer's Disease: Relationship to Severity of Dementia and Apolipoprotein E Genotype. Neurology, 50, 164-168. http://dx.doi.org/10.1212/WNL.50.1.164

[12] Burns, J.M., Honea, R.A., Vidoni, E.D., Hutfles, L.J., Brooks, W.M. and Swerdlow, R.H. (2012) Insulin Is Differentially Related to Cognitive Decline and Atrophy in Alzheimer’s Disease and Aging. Biochimica et Biophysica Acta, 1822, 333-339. http://dx.doi.org/10.1016/j.bbadis.2011.06.011

[13] Seleem, W.M., Atiyah, M.M., Hamed, E.F., Abd-Elrahman, A.M.N., Algerby, M.M. and Abdin, H. (2012) Frailty: Identification and Markers. British Journal of Science, 7, 80-92.

[14] Muller, A.P., Gnoatto, J., Moreira, J.D., Zimmer, E.R., Haas, C.B., Lulhier, F., Perry, M.L., Souza, D.O., Torres-Aleman, I. and Portela, L.V. (2011) Exercise Increases Insulin Signaling in the Hippocampus: Physiological Effects and Pharmacological Impact of Intra Cerebroventricular Insulin Administration in Mice. Hippocampus, 21, 1082-1092. http://dx.doi.org/10.1002/hipo.20822

[15] D’Alessandris, C., Lauro, R., Presta, I. and Sesti, G. (2007) C-Reactive Protein Induces Phosphorylation of Insulin Receptor Substrate-1 on Ser307 and Ser 612 in L6 Myocytes, Thereby Impairing the Insulin Signalling Pathway That Promotes Glucose Transport. Diabetologia, 50, 840-849. http://dx.doi.org/10.1007/s00125-006-0522-y

[16] Carro, E., Nunez, A., Busiguina, S. and Torres-Aleman, I. (2000) Circulating Insulin-Like Growth Factor I Mediates Effects of Exercise on the Brain. Journal of Neuroscience, 20, 2926-2933.

[17] Puts, M.T.E., Visser, M., Twisk, J.W.R., Deeg, D.J.H. and Lips, P. (2005) Endocrine and Inflammatory Markers as Predictors of Frailty. Clinical Endocrinology, 63, 403-411.

[18] Barzilay, J.I., Blaum, C., Moore, T., Xue, Q.L., Hirsch, C.H., Walston, J.D. and Fried, L.P. (2007) Insulin Resistance and Inflammation as Precursors of Frailty: The Cardiovascular Health Study. JAMA Internal Medicine, 167, 635-641. http://dx.doi.org/10.1001/archinte.167.7.635 
[19] El-Okl, M.A. (2002) Prevalence of Alzheimer Dementia and Other Causes of Dementia in Egyptian Elderly. MD Thesis, Faculty of Medicine, Ain Shams University, Cairo.

[20] Shehta, A.S., El-Banouby, M.H., Mortagy, A.K. and Ghanem, M. (1998) Prevalence of Depression among Egyptian Geriatric Community. Geriatric Department Library, Ain Shams University, Cairo, 3-5.

[21] Fried, L.P., Tangen, C.M., Walston, J., Newman, A.B., Hirsch, C., Gottdiener, J., Seeman, T., Tracy, R., Kop, W.J., Burke, G., McBurnie, M.A., Cardiovascular Health Study Collaborative Research Group (2001) Frailty in Older Adults: Evidence for a Phenotype. Journal of Gerontology: Medical Sciences, 56A, M146-M156.

[22] Orme, J.G., Reis, J. and Herz, E.J. (1986) Factorial and Discriminant Validity of the Center for Epidemiological Studies Depression (CES-D) Scale. Journal of Clinical Psychology, 42, 28-33. http://dx.doi.org/10.1002/1097-4679(198601)42:1<28::AID-JCLP2270420104>3.0.CO;2-T

[23] Gladsjo, J.A., Schuman, C.C., Evans, J.D., Peavy, G.M., Miller, S.W. and Heaton, R.K. (1999) Norms for Letter and Category Fluency: Demographic Corrections for Age, Education, and Ethnicity. Assessment, 6, 147-178. http://dx.doi.org/10.1177/107319119900600204

[24] Melika, L.K. (1991) Wechsler Intelligence Scale for Adults and Adolescents. Cairo El-Nahda Egyptian Library, 91, 92-101.

[25] Luria, A.R. (1966) Higher Cortical Functions in Man. Basic Books, New York.

[26] El-Sherpiny, M., Mortagy, A. and Fahy, H. (2000) Prevalence of Hypercholesterolemia among Elderly People Living in Nursing Houses in Cairo. Geriatric Department Library, Ain Shams University, Cairo, 6.

[27] Fillenbaum, G. (1986) The Wellbeing of the Elderly: Approaches to Multi-Dimensional Assessment. World Health Organization, WHO Offset Publication No. 84, Arabic Translation Distributed by the Eastern Mediterranean Regional Office.

[28] Matthews, D.R., Hosker, J.P., Rudenski, A.S., Naylor, B.A., Treacher, D.F. and Turner, R.C. (1985) Homeostasis Model Assessment: Insulin Resistance and $\beta$-Cell Function from Fasting Glucose and Insulin Concentrations in Man. Diabetologia, 28, 412-419. http://dx.doi.org/10.1007/BF00280883

[29] Wallace, T.M., Levy, J.C. and Matthews, D.R. (2004) Use and Abuse of HOMA Modeling. Diabetes Care, 27, 14871495. http://dx.doi.org/10.2337/diacare.27.6.1487

[30] Bonora, E., Targher, G., Alberiche, M., Bonadonna, R.C., Saggiani, F., Zenere, M.B., Monauni, T. and Muggeo, M. (2000) Homeostasis Model Assessment Closely Mirrors the Glucose Clamp Technique in the Assessment of Insulin Sensitivity: Studies in Subjects with Various Degrees of Glucose Tolerance and Insulin Sensitivity. Diabetes Care, 23, 57-63. http://dx.doi.org/10.2337/diacare.23.1.57

[31] Negami, M., Takahashi, E., Otsuka, H. and Moriyama, K. (2012) Prediction of Homeostasis Model Assessment of Insulin Resistance in Japanese Subjects. The Tokai Journal of Experimental and Clinical Medicine, 37, 102-106.

[32] Calori, G., Lattuada, G., Piemonti, L., Garancini, M.P., Ragogna, F., Villa, M., Mannino, S., Crosignani, P., Bosi, E., Luzi, L., Ruotolo, G. and Perseghin, G. (2011) Prevalence, Metabolic Features, and Prognosis of Metabolically Healthy Obese Italian Individuals: The Cremona Study. Diabetes Care, 34, 210-215. http://dx.doi.org/10.2337/dc10-0665

[33] Saudek, C.D., Herman, W.H., Sacks, D.B., Bergenstal, R.M., Edelman, D. and Davidsonon, M.B. (2008) A New Look at Screening and Diagnosing Diabetes Mellitus. Journal of Clinical Endocrinology \& Metabolism, 93, 2447-2453. http://dx.doi.org/10.1210/jc.2007-2174

[34] Kaplan, R.J., Greenwood, C.E., Winocur, G. and Wolever, T.M. (2000) Cognitive Performance Is Associated with Glucose Regulation in Healthy Elderly Persons and Can Be Enhanced with Glucose and Dietary Carbohydrates. American Journal of Clinical Nutrition, 72, 825-836.

[35] Euser, S.M., Sattar, N., Witteman, J.C.M., Bollen, E.L., Sijbrands, E.J., Hofman, A., Perry, I.J., Breteler, M.M., Westendorp, R.G. and for PROSPER and the Rotterdam Study (2010) A Prospective Analysis of Elevated Fasting Glucose Levels and Cognitive Function in Older People Results from PROSPER and the Rotterdam Study. Diabetes, 59, 16011607. http://dx.doi.org/10.2337/db09-0568

[36] Swinburn, B.A. (1996) The Thrifty Genotype Hypothesis: How Does It Look after 30 Years? Diabetic Medicine, 13, 695-699. http://dx.doi.org/10.1002/(SICI)1096-9136(199608)13:8<695::AID-DIA170>3.0.CO;2-\#

[37] Mielke, M.M., Zandi, P.P., Sjogren, M., Gustafson, D., Ostling, S., Steen, B. and Skoog, I. (2005) High Total Cholesterol Levels in Late Life Associated with a Reduced Risk of Dementia. Neurology, 64, 1689-1695. http://dx.doi.org/10.1212/01.WNL.0000161870.78572.A5

[38] Sanz, C., Andrieu, S., Sinclair, A., Hanaire, H., Vellas, B. and for the REAL.FR Study Group (2009) Diabetes Is Associated with a Slower Rate of Cognitive Decline in Alzheimer Disease. Neurology, 73, 1359-1366. http://dx.doi.org/10.1212/WNL.0b013e3181bd80e9

[39] Craft, S., Baker, L.D., Montine, T.J., Minoshima, S., Watson, G.S., Claxton, A., Arbuckle, M., Callaghan, M., Tsai, E., 
Plymate, S.R., Green, P.S., Leverenz, J., Cross, D. and Gerton, B. (2012) Intranasal Insulin Therapy for Alzheimer Disease and Amnestic Mild Cognitive Impairment: A Pilot Clinical Trial. JAMA Neurology, 69, 29-38. http://dx.doi.org/10.1001/archneurol.2011.233

[40] de Kloet, A.D., Pacheco-López, G., Langhans, W. and Brown, L.M. (2011) The Effect of TNF $\alpha$ on Food Intake and Central Insulin Sensitivity in Rats. Physiology \& Behavior, 103, 17-20. http://dx.doi.org/10.1016/j.physbeh.2010.11.037

[41] Ide, K. and Scher, N.H. (2000) Cerebral Blood Flow and Metabolism during Exercise. Progress in Neurobiology, 61, 397-414. http://dx.doi.org/10.1016/S0301-0082(99)00057-X

[42] Molteni, R., Ying, Z. and Gomez-Pinilla, F. (2002) Differential Effects of Acute and Chronic Exercise on PlasticityRelated Genes in the Rat Hippocampus Revealed by Microarray. European Journal of Neuroscience, 16, 1107-1116. http://dx.doi.org/10.1046/j.1460-9568.2002.02158.x

[43] Vijayakumar, T.M., Sirisha, G.B.N., Farzana Begam, M.D. and Dhanaraju, M.D. (2012) Mechanism Linking Cognitive Impairment and Diabetes Mellitus. European Journal of Applied Sciences, 4, 1-5. 